\title{
Topical Therapy of Skin Scabs in Psoriasis with Salicylic Acid: Case Report
}

\author{
Wilfredo Molina Wills DDs, Ms, PHd ${ }^{1 *}$; Vanessa Rodriguez DDs² \\ ${ }^{1}$ Researcher of the histology department of the medicine school of the University of Los Andes Venezuela. \\ ${ }^{2}$ private practice, Venezuela.
}

*Corresponding Author: Wilfredo Molina Wills, Researcher of the histology department of the medicine school of the University of Los Andes Venezuela.

\section{Received Date: 22 November 2021 | Accepted Date: 29 December 2021 | Published Date: 06 January 2022}

Citation: Wilfredo M Wills; V Rodriguez. (2022). Topical Therapy of Skin Scabs in Psoriasis with Salicylic Acid: Case Report. International Journal of Clinical Case Reports and Reviews. 10(2); DOI: 10.31579/2690-4861/193

Copyright: (c) 2022 Wilfredo Molina Wills, This is an open-access article distributed under the terms of the Creative Commons Attribution License, which permits unrestricted use, distribution, and reproduction in any medium, provided the original author and source are credited.

\begin{abstract}
The objective was to evaluate the keratolytic and anti-inflammatory action of salicylic acid in the affected area in the case reported.

Methods: Clinical photography, A digital camera was used Olympus SP570UZ with master software 2.0. The images obtained both in the initial phase without treatment and at the 72 hours of treatment were transferred and stored on a 4-core Sansung computer. The autodial adjustment option was selected. In this way, the camera selects the optimal way to take the photo shot. Analysis of the affected skin with scales and scabs. Image $\mathbf{J}$ software was used to measure the area selected for the study in both cases. This measurement was made in pixels for the photographic region under study.

Results: The image $\mathrm{j}$ software program measures the areas in pixels, to decrease in measurement error there was no calibration. That is, the measurement of the areas in pixels was maintained. The percentage ratios of the affected or non-affected areas for both left and right legs are presented in Tables. It is possible to observe the reduction of the affected area. The doubtful areas represent for the left leg $5.21 \%$ and for the right leg $30.08 \%$ after treatment. Only a clearly visible area with crusts and scabs of $1.60 \%$ was observed after treatment.
\end{abstract}

Key words: psoriasis; skin scales and scabs; salicylic acid; topical treatment of psoriasis

\section{Introduction}

Chronic plaque psoriasis is the most common type. Usually these plaques are erythematous. They can be observed on the trunk, buttocks, and limbs and anywhere on the body [1]. They have also been associated with seborrheic dermatitis on the scalp [2] and commonly these lesions are associated with itching and a feeling of dry skin.

Commonly these lesions are associated with itching and a feeling of dry skin. In topical therapy, the use of corticosteroids [3], vitamin D3 20, phototherapy [4], and biological therapy [5] have been considered.

Have been mentioned, that when using multiple topical agents, it is important to be aware of possible compatibility issues, for example, salicylic acid inactivates calcipotriene [6]. Salicylic acid leads to desquamation of corneocytes through two pathways. It reduces intercellular cohesiveness of the horny cells by dissolving the intercellular cement material [7]. In the therapy of psoriasis, Salicylic acid significantly increases the penetration rate of the others topical substances because of its keratolytic effects [8]. The objective of this case report was to evaluate the action of salicylic acid on the scales and scabs of an affected area in a patient with psoriasis.

\section{Methods}

In this study, one case with psoriasis of the skin was reported.

\section{Study of the affected area}

The scalp area of the frontal region was selected in both cases. Aspects such as the presence of scabs and hyperkeratosis were evaluated before and after treatment.

\section{Clinical photography}

A digital camera was used Olympus SP570UZ with master software 2.0. The images obtained both in the initial phase without treatment and at the 72 hours of treatment were transferred and stored on a 4-core Sansung computer. The auto-dial adjustment option was selected. In this way, the camera selects the optimal way to take the photo shot.

\section{Focus and exposure position}

Horizontal and vertical focus orientations as well as exposure were maintained during initial and post-treatment. The sequential firing speed was fast at 13.5 frames per second. 


\section{Inclusion criteria}

Only areas where scabs were clearly visible both before and after treatment were accepted to be measured and subsequently compared. All very small or confusing areas were discarded.

\section{Evaluated area}

The area evaluated was from the lower, lateral and internal edge of the knee patella to the area of the proximal phalanx of the feet.

\section{Statistical procedure}

In both legs, the areas with scabs were measured. For both the left and right legs, the affected areas were added before the treatment. The percentages of these areas were then compared with the areas where scabs persist after treatment.

\section{Analysis of the affected skin with scabs}

Image $\mathbf{J}$ software was used to measure the area selected for the study in both cases. This measurement was made in pixels for the photographic region under study. This method allowed us to analyze the amount of area affected and compare it before and after treatment by evaluating tissue changes if there are any during the application of the formula containing in its salicylic acid composition. In this way it was possible to quantify the amount of area where the inflammatory process, erythematic, or scab formation persists. Physicochemical and microbiological analysis of the formula. Before its application, the shampoo formula was subjected to a micro biological and physicchemical study carried out by Cima laboratory in Venezuela. The pre-use physicchemical analysis in treated cases was dimensional, $\mathrm{pH} 6.3$ being the established regulations, and values of 3-10. The previous microbiological analysis was: UFC/ml escherichia coli units absent, pseudomona aeruginosa 0 , fungus $<1$, yeasts $<1$, and staphylococcus aureus absent. These previous results allow framing the product within the established standards and values.

\section{Case 1}

Male patient of 55 years old, weighing 74 kilograms and a height of 1.80 meters. The patient reports itching, dryness of the skin and a feeling of tightness in both legs. Clinically it was possible to observe the presence of scabs and scaly hyperkeratosis disseminated by both legs. Dermatological diagnosis confirmed the presence of psoriasis. Figure 1. The chronology of psoriasis is from adolescence. The patient reports that he frequently suffers from sadness and depression. In the same way, it states that when the stages of depression are accentuated, the presence of plaques also increases.

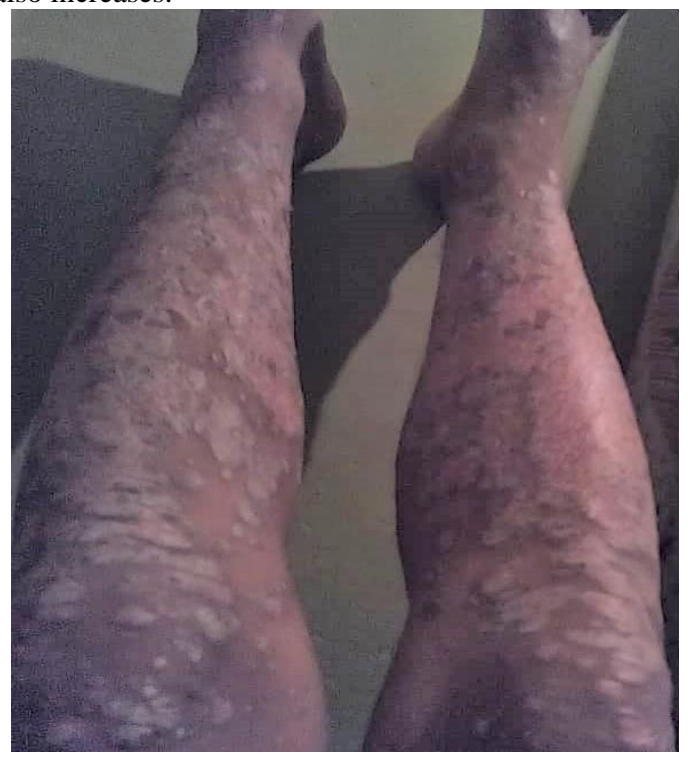

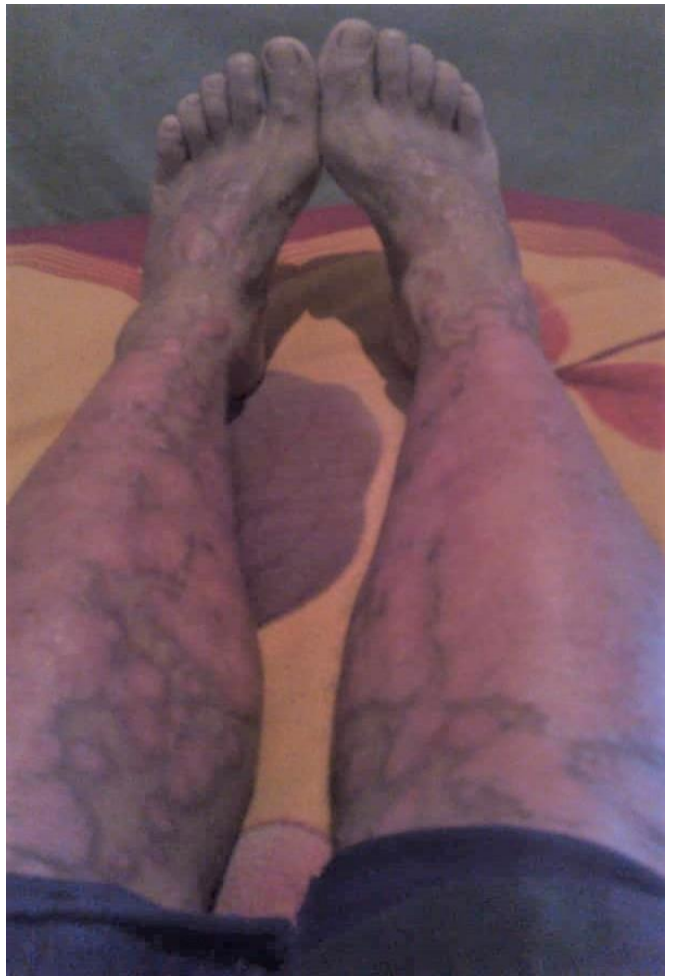

\section{Results}

The image $\mathrm{j}$ software program measures the areas in pixels, to decrease in measurement error there was no calibration. That is, the measurement of the areas in pixels was maintained. The percentage ratios of the affected or non-affected areas for both left and right legs are presented in Tables 1 and 2 .

\section{Table 1}

\begin{tabular}{|l|l|l|}
\hline Left leg & Areas & Percentages \\
\hline Total area & 88955 & $100 \%$ \\
\hline Affected area & 78327 & $88,05 \%$ \\
\hline Affected area after treatment & 5997 & $6,74 \%$ \\
\hline
\end{tabular}

In Table1, it is possible to observe the reduction of the affected area. The doubtful areas represent for the left leg $5.21 \%$ and for the right leg $30.08 \%$ after treatment.

Table 2

\begin{tabular}{|l|l|l|}
\hline Right leg & Areas & Percentages \\
\hline Total area & 99487 & $100 \%$ \\
\hline Affected area & 63999 & $64,32 \%$ \\
\hline Affected area after treatment & 1597 & $1,60 \%$ \\
\hline
\end{tabular}

Only a clearly visible area with crusts and scabs of $1.60 \%$ was observed after treatment.

\section{Discussion}

In the reported case, the rapid scaly process of psoriasis scales in the affected areas was clearly visible. The effect of salicylic acid in shampoo form appears to contribute efficiently to the removal of scales and hyperkeratosis of psoriasis. There is a vast array of vehicles including creams, gels, solutions, foams, sprays, shampoos, and lotions. Different vehicles are indicated for different body sites. Scalp is commonly involved in psoriasis and requires gel, solutions, or foams that are not as messy as ointments and creams. Has been reported that Topical agents can be used intermittently or continuously. Agents that are more potent 
must be used on a short-term basis to allow for response, and then patients should be instructed to use these agents intermittently for long-term management. This strategy may reduce the risk of side effects [9].

\section{Conclusion}

Topical salicylic acid therapy in the form of shampoo is a safe and tolerable way to remove skin scales in patients with psoriasis.

\section{References}

1. Canadian psoriasis guidelines committee. (2009). Canadian guidelines for management of plaque psoriasis. Otawa, on: Canadian Dermatology association.

2. Wilfredo Molina Wills and Vanessa Rodríguez. (2020). Keratolitic and anti-inflamatory action of salicylic acid in patients with seborrheic dermatitis associated with psoriasis, medico research chronicles, Cases report. 7(4).

3. Menter A, Korman NJ, Elmets CA, Feldman SR, Gelfand JM, Gordon KB, et al. (2009). Guidelines of care for the management of psoriasis and psoriatic arthritis. Section 3. Guidelines of care for the management and treatment of psoriasis with topical therapies. J Am Acad Dermatol. 60(4):643-659.
4. Menter A, Korman NJ, Elmets CA, Feldman SR, Gelfand JM, Gordon KB, et al. (2010). Guidelines of care for the management of psoriasis and psoriatic arthritis: section 5 . Guidelines of care for the treatment of psoriasis with phototherapy and photochemotherapy. J Am Acad Dermatol. 62(1):114-135.

5. Lin VW, Ringold S, Devine EB. (2012). Comparison of ustekinumab with other biological agents for the treatment of moderate to severe plaque psoriasis: a Bayesian network metaanalysis. Arch Dermatol. 148(12):1403-1410.

6. Del Rosso J. (2005). Pharmacotherapy updates: Current therapies and research for common dermatologic conditions. The many roles of salicyclic acid. Skin Aging. 13:38-42.

7. Lebwohl M. (1999). The role of salicylic acid in the treatment of psoriasis. Int J Dermatol. 38:16-24.

8. Tiplica GS, Salavastru CM. (2009). Mometasone furoate $0.1 \%$ and salicylic acid $5 \%$ vs. mometasone furoate $0.1 \%$ as sequential local therapy in psoriasis vulgaris. J Eur Acad Dermatol Venereol. 23:905-912.

9. Green PG, Forbes DR, Kennedy CTC. (1985). The stability of dithranol in various bases. Br J Dermatol. 113(s29):26.
This work is licensed under Creative Commons Attribution 4.0 License

To Submit Your Article Click Here: $\quad$ Submit Manuscript
Ready to submit your research? Choose Auctores and benefit from:

$>$ fast, convenient online submission

$>$ rigorous peer review by experienced research in your field

$>$ rapid publication on acceptance

$>$ authors retain copyrights

$>$ unique DOI for all articles

$>$ immediate, unrestricted online access

At Auctores, research is always in progress.

Learn more https://auctoresonline.org/journals/international-journal-of-clinicalcase-reports-and-reviews 